\title{
Using of Wide Stopes in Coalless Zones Mined by Shovels and Backhoes
}

\author{
Valery Kolesnikov ${ }^{1,{ }^{*}}$, Oleg Litvin ${ }^{1}$, Juraj Janočko ${ }^{2}$, and Andrey Efremenkov ${ }^{3}$ \\ ${ }^{1}$ T.F. Gorbachev Kuzbass State Technical University, 28 Vesennyaya st., Kemerovo, Russian Federa- \\ tion, 650000 \\ ${ }^{2}$ Technical University of Kosice, Faculty of Mining, Ecology, Process Control and Geotechnologies, \\ Letná 9, 04200 Kosice, Slovak Republic \\ ${ }^{3}$ Yurga Institute of Technology, TPU Affiliate, 26 Leningradskaya st., Yurga 652050, Russian Feder- \\ ation
}

\begin{abstract}
The examples of mining rock panels by different types of equipment are given in this paper. In such conditions, it is most expedient to use wide stopes to improve the productivity of equipment by reducing the time for auxiliary works. Also technological schemes of equipment operation in different conditions for several quarries of the Kuzbass are proposed. The coal-bearing zone is worked "layer by layer" with one or two benches or subbenches. The bottom of the quarry in this case is flat, without leaving "peak" of overburden rocks in the pillars. Cutting of the benches is carried out by trench with a wide bottom on the side of the roof of the coal bed and simultaneously working it with the same excavator or with setting up a additional excavator for coal mining operations. Interbeds are mined out with the use of wide stopes, often to the theirs entire horizontal width. Complex rock-and-coal blocks, including one-three coal beds, are also worked out by wide stopes.
\end{abstract}

\section{Introduction}

In the total volume of rock-and-coal mass in quarry fields, the coal-bearing zone consists $72-84 \%$ in the deposits of the central Kuzbass and about $70 \%$ in the deposits of the north and south of the basin. From the standpoint of the separate excavation of coal and rock, the coal-bearing zone is a complex structure, which is determined by the bedding of coal strata of varying thickness and angles of incidence; the presence of thin rock interpbeds, folding (plicative dislocations), disturbance and hard bedrocks (strength limit 60-80 MPa, less often up to $130 \mathrm{MPa}$ ). Uncertainty of capacity and frequent variability of elements of occurrence of separate rock layers within the limits of a quarry field both in length, and in depth are observed. Thus, the development of the coal-bearing zone represents the main difficulty in the open pits, and consequently, the increase in the efficiency of surface mining is directly related to creating of new technological and technical solutions.

*Corresponding author: ormpi@kuzstu.ru 
It should be noted that in the classical theory of open mining, the concept of "coalbearing zone" for bed deposits is absent. Describing the theory of development of open pit mining on inclined and steep deposits, the development of just one layer is considered.

In this case, the width of the bottom of the pit is equal to the horizontal width of the coal seam.

\section{Theory}

The development of coal-bearing zones by different types of excavation equipment was considered in a number of articles [1-8]. It is recommended to develop of coal-bearing areas (zones) by subbenches (sublayers). In this case, excessive coal losses are excluded, because the approach of mining to each of the strata is always carried out from the side of the hanging side (the roof of the formation).

Experience has shown that when shovels work in a coal-bearing zone, the change in the type of excavator work (the transition from coal extraction to overburden) occurs relatively frequently (up to 3-5 times a month). As a result of such transitions, the use of the excavator in the main work (excavation and loading of the overburden) deteriorates and its productivity decreases by $18-20 \%$.

Along with the complex operating conditions of machines in the face, there are some features of the opening-up and preparation of new horizons (benches). For example, the opening-up of benches is carried out during the whole period of exploitation of the quarry, and the methods of opening-up of individual benches or their groups may be different (external or internal trenches, sliding trenches). Preparation of working benches, as a rule, is carried out simultaneously along several of the thickest beds of the formation.

The notion of a "wide stope" was formulated in [9], where it is noted that its development is characterized by the variable (shuttle) direction of the excavator's movement in the plan. The use of wide stopes is possible with maneuverable quarry trucks, what simplifies the organization of mining operations.

\section{Results and discussion}

Cutting of the behches by trenches with a wide bottom and working out of the coal-androck blocks by wide stopes with the use of shovels is shown in Fig. 1 on the example of the "Bachatsky" open pit.

As it shown on Fig.1, the width of the trench bottom is $53 \ldots 120 \mathrm{~m}$ when cutting a new bench. The trench can be worked out both in interbeds without coal mining operations (Figure 1-a), and with them (Figures 1-b, 2-a, 2-b). On a open pit "Bachatsky" when coal dip angles are $60 \div 75^{\circ}$, the excavation of coal beds is made to the full height of the bench.

The application of wide stopes on some of Kuzbass open pits for working out by backhoes is shown in Fig. 3. As can be seen from this table, wide stopes are using for interbeds mining. The width of the stope is $40 \div 65 \mathrm{~m}$. The benches are mined by layers of $3 \div 5 \mathrm{~m}$, usually $4 \mathrm{~m}$.

Shovels do not always ensure a high efficiency of development of mineral deposits due to their inconsistency with working conditions. It is manifested in the limited choice of the location of the transport setting for loading (only on the level of the excavator standing), at a low height of the formation of the soil (roof) of the formation, in particular, at dip angles of incidence $15-50^{\circ}$, in the inability to provide the specified angle of the slope of the face, in the need to create wide cut trenches. These disadvantages are particularly noticeable in difficult conditions, but they are almost uncharacteristic of backhoes, which has the ability to dig below the level of standing of the excavator. 


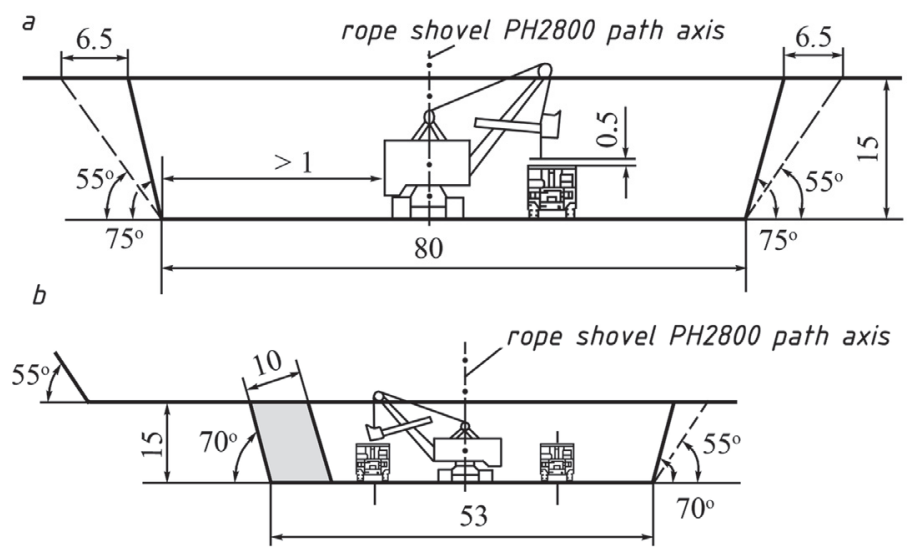

Fig. 1. Using of wide stopes for coal-bearing zone excavation on open pit "Bachatsky": a - cutting of new bench on thick interbed; $b$ - cutting of new bench with simultaneous coal extraction on seam Burned.
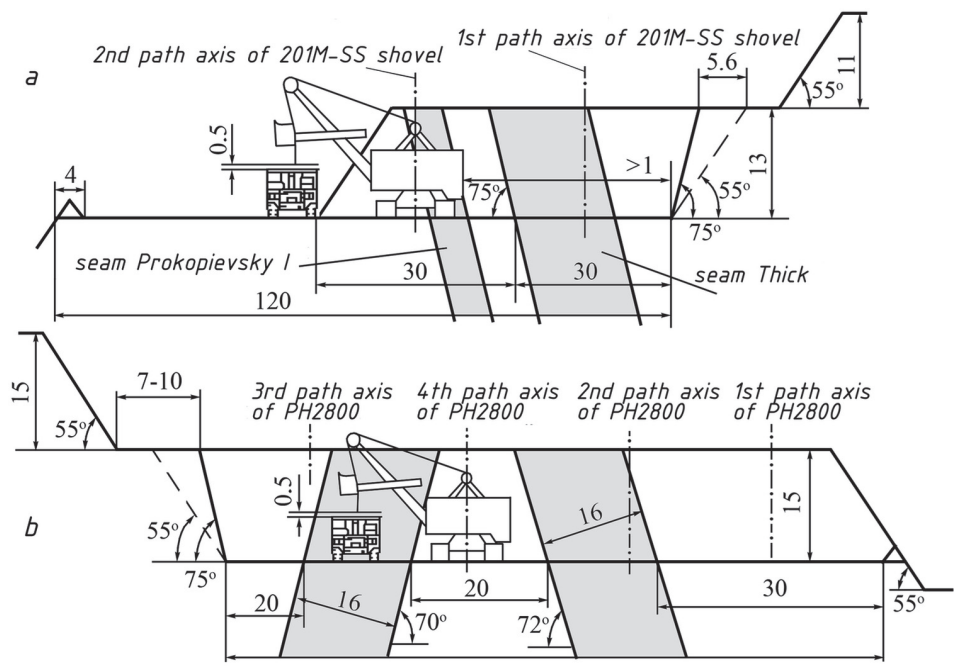

Fig. 2. Selective mining of hard-structural stope including two nearby seams: a - stope includes two close located seams Prokopievsky I and Thick; $b$ - stope included seam Burned in zone of its plicative dislocation (left and right wings of fold).

When using such machines, there is no need to set transport on the excavation horizon. The excavator has a great digging force, changing trajectory of the bucket during all the operations of the cycle; the overall dimensions of the excavators are relatively small, which is very important for the development of complex coal-bearing zones, often with an unsettled occurrence of seams and a variety of forms of their location in the stope.

A feature of the technology with backhoe is the maximum use of shunting capabilities of dump trucks due to their selective setting at the bottom of the bench in conditions of work with the bottom loading. As a result, the minimum value of the angle of rotation of the excavator is ensured, which does not depend on the width of the stope.

The cutting of a new bench with the making of coal mining operations, both for inclined beds and for steep ones is made by wide stopes from 30 to $100 \mathrm{~m}$. The cutting trenches are also excavated by layers (subbenches). 

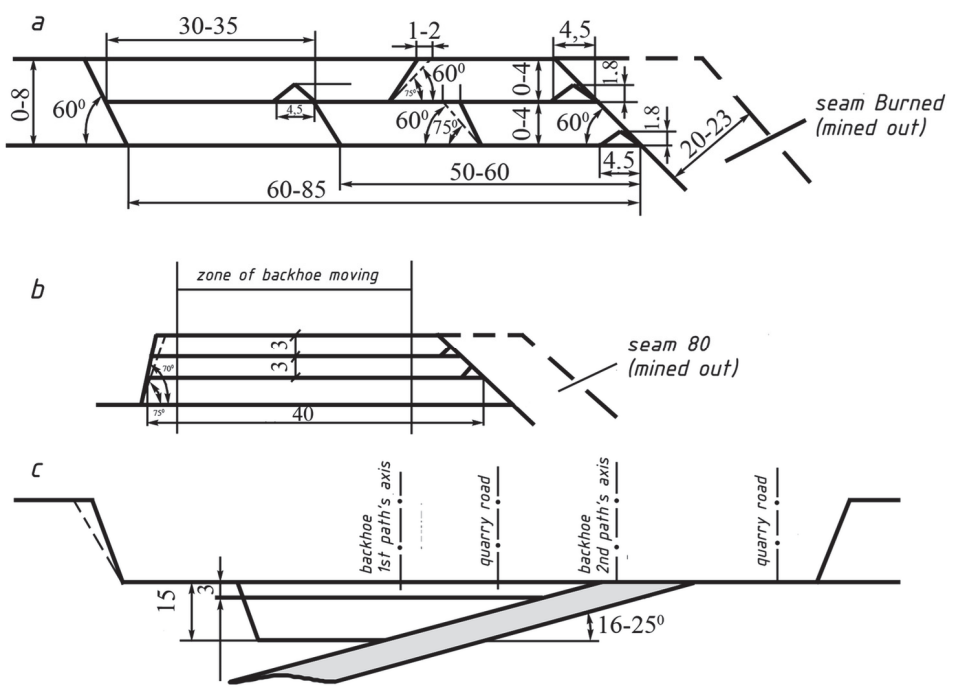

Fig. 3. Excavation of interbed by backhoe: a - open pit mine "Krasnobrodsky" after mining out seam Burned, backhoe Terex RH-200; b - open pit mine "Taldinsky" after mining out seam 80, backhoe Liebherr R9350; c - cutting of new bench on open pit mine "Kedrovsky", backhoe Caterpillar 385C.

\section{Conclusion}

Based on the analysis we can conclude the following.

1. At present, a wide range of excavator models of the following types is used for the development of coal-bearing zones: rope shovels, hydraulic shovels, backhoes. For the mining of rock interbeds, rope shovels with bucket capacity of $5 . .30 \mathrm{~m}^{3}$ and, less often backhoes with a bucket capacity of $3.4 \ldots 7 \mathrm{~m}^{3}$ are used.

2. Cutting of the benches is carried out by trenches with a width on the bottom from 53 $\mathrm{m}$ to $120 \mathrm{~m}$ from the side of the roof of the coal bed and simultaneously working it with the same excavator or with the setting of additional excavator for coal mining operations. Interbeds are worked out with the widespread use of wide stopes with horizontal width up to $100 \mathrm{~m}$. Complex rock-and-coal blocks, including one-three layers, are also worked out by wide stopes.

\section{References}

1. E.I. Vasil'ev, V.F. Kolesnikov, Soviet Mining Science 5, 532 (1969)

2. P.M. Alabuzhev, O.D. Alimov et al., Soviet Mining, 2, 183 (1966)

3. Yu.I. Belyakov, V.E. Boguslavskii and S.A. Skachkov, Soviet Mining, 21, 165 (1985)

4. B.N. Lokhanov, Y.A. Zakharov et al., Sov. Min., 3, 523 (1967)

5. M.M. Bereznyak, A.V. Kalinin and V.G. Pronoza, Soviet Mining 6(6), 638 (1970)

6. I.V. Nazarov, J. Min. Sci., 48, 55 (2011)

7. N. Demirel, J. Min. Sci., 47, 441 (2011)

8. I. Vukotic, V. Kecojevic, W. Zhang, Q. Cai, Int. J. Min. Sci. Tech., 23, 901 (2013)

9. Rzhevsky V.V. Open pit mining (Nedra, Moscow, 1985) 